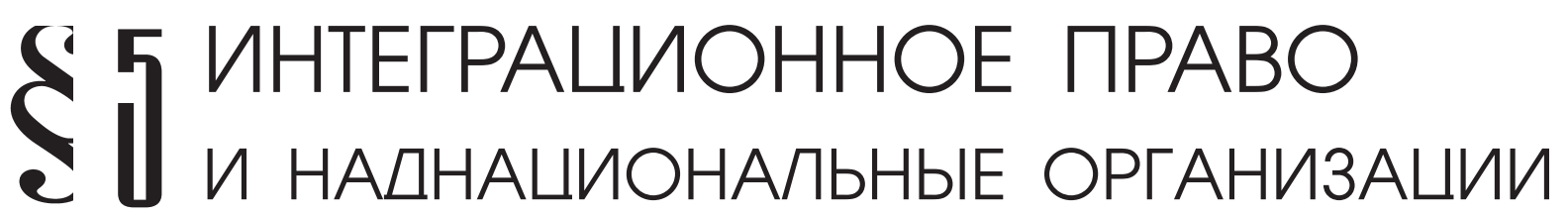

Резник P.C.

\section{КОЛЛИЗИОННАЯ ЗАЩИТА ПРАВ ПОТРЕБИТЕЛЕЙ В ЕВРОПЕЙСКОМ СОЮЗЕ И РОССИЙСКОЙ ФЕДЕРАЦИИ}

\begin{abstract}
Аннотация: В статье рассмотрены модели коллизионного регулирования договоров с участием потребителя, отдельно изучается модель, избранная российским и европейским законодателем. Раскрыты понятия пассивных и активных потребителей, отражены особенности регулирования договоров с участием каждого из этих видов потребителей. На основе анализа норм и доктрины выявлен ряд практических и теоретических проблем. Так, поднимается вопрос о возможности кумулятивного применения защитных императивных норм нескольких правопорядков. Сохраняется неясность в вопросе о том, по чьей инициативе применяются императивные нормы страны места жительства потребителя - самого потребителя или суда ех оfficio. Кроме того, в доктрине поднимается вопрос, какие именно императивные нормы подлежат применению - только те, что касаются непосредственно защиты прав потребителей, или вообще любые императивные нормы права страны места жительства потребителя. Другой проблемой для практики является необходимость профессиональной стороны учитывать и знать законодательство о защите прав потребителей всех стран, в которые она направляет свою деятельность, что влечет дополнительные издержки для малого и среднего бизнеса, вытесняя его из международной розничной торговли. Внесено предложение прямо запретить кумулятивное применение защитных императивных норм нескольких правопорядков, ограничить круг применимых императивных норм сферой защиты прав потребителей.
\end{abstract}

Ключевые слова: Потребительский договор, коллизионное право, Европейский союз, автономия воли сторон, императивные нормы, защита прав потребителя, международная торговля, активные потребители, пассивные потребители, нацеленная деятельность.

Abstract: This article examines the models of choice of law regulation of contracts involving consumers, while separately studying the model chosen by Russian and European legislators. The work explains the notions of passive and active consumers, and reflects the specificity of contract regulation with participation of both of these types of consumers. Based on the analysis of the norms and doctrines, the author determines a number of practical and theoretical problems, thus raising the issue of possibility of the cumulative application of protective imperative norms of several legal orders. It is yet unclear who initiates the application of imperative norms of the country of residence of the consumer - the consumer or the ex officio court. In addition to that, the author raises the question of exactly which imperative norms are subject to application - only those that directly pertain to consumer protection, or any imperative norms of the consumer's country of residence. Another practical issue is the need for the professional side to consider and know the legislation on consumer protection of all countries in which they conduct business, which carries additional expenses for small and medium business, forcing it out of the international retail market.

Keywords: Passive consumers, active consumers, international trade, consumer protection, mandatory norms, party autonomy, European Union, choice of law, consumer agreement, targeted activity.

ажную роль в структуре трансграничных экономических связей составляет международная розничная торговля. Сегодня, когда возможности электронной коммерции позволяют осуществлять заказ товаров практически из любой точки земного шара, приобретают особую актуальность вопросы защиты прав потребителей в контексте международного частного права (далее - МЧП).
В то время как во внутренних отношениях права потребителей в подавляющем большинстве развитых стран подлежат материально-и процессуально-правовой защите, в трансграничных правоотношениях перечень видов защиты расширяется. Помимо унифицированных материальных норм о правах потребителей, а также международных унифицированных и национальных норм об определении юрисдикции по спорам из договоров с участием 
потребителя, права последнего в МЧП защищаются также международными унифицированными и национальными коллизионными нормами. Сами по себе коллизионные нормы не содержат в себе конкретные способы защиты прав, однако, как будет продемонстрировано ниже, они выстраивают такой механизм регулирования, который, в конечном счете, ведет к применению наиболее благоприятных для потребителя национальных норм.

Российский законодатель в вопросах коллизионного регулирования отношений из договора с участием потребителя давно следует примеру Европейского союза (ЕС). Правила выбора применимого права к договорам с участием потребителя были впервые закреплены уже в третьей части Гражданского кодекса Российской Федерации [1] (ГК РФ) в редакции от 26.11.2001 г., в ст. 1212. Они соответствовали европейской модели, содержавшейся в подписанной в Риме в 1980 г. Конвенции о праве, подлежащем применению к договорным обязательствам [2] (далее - Римская конвенция). Позднее европейская модель подверглась достаточно серьезным изменениям; в новом виде она содержится в ст. 6 Регламента № 593/2008 Европейского парламента и Совета от 17 июня 2008 г. о праве, подлежащем применению к договорным обязательствам [3] (далее - Рим I). И снова российский законодатель взял европейское регулирование за образец, внеся Федеральным законом от 30.09.2013 № 260-ФЗ аналогичные изменения в ст. 1212 ГК РФ [4].

Прежде всего, необходимо отметить, что как в Регламенте Рим I, так и в ГК РФ автономия воли сторон остается генеральной коллизионной привязкой: стороны договора с участием потребителя вправе самостоятельно выбрать право, подлежащее применению к их договору. Относительно допустимости автономии воли в трансграничных договорах с участием потребителя в доктрине выделяют несколько моделей регулирования.

Так, современный немецкий исследователь Г. Рюль говорит о трех моделях регулирования [5, c. 588]: недопустимость, ограничение и «укорачивание» автономии воли сторон. Российский коллизионист А. В. Асосков, в свою очередь, придерживается классификации, предложенной английским исследователем Дж. Хиллом [6, с. 37], и выделяет четыре модели коллизионного регулирования договоров с участием потребителя [7, с. 149]: отсутствие специальных ограничений автономии воли; полная недопустимость автономии воли; установление исчерпывающего перечня правопорядков, доступных для выбора; приоритет защитных императивных норм права по месту жительства потребителя.
Как указывает А. В. Асосков, первая модель отсутствие специальных ограничений автономии воли - не предполагает введения специальных ограничений автономии воли для договоров с участием потребителя, а, если точнее, - специального коллизионного регулирования вообще. В качестве примера приводится Гаагская конвенция 1955 г. о праве, применимом к международной купле-продаже товаров, которая не исключает из сферы своего действия договоры с участием потребителя и в то же время не предусматривает для них какого-либо специального коллизионного регулирования.

Думается, что в данном случае едва ли стоит говорить о какой-либо модели регулирования, поскольку на момент принятия данной конвенции правовая парадигма еще вовсе не знала концепции защиты прав потребителя, которая возникла только в 1960-е гг.

Английский исследователь Т. Хартли полагает, что специальное коллизионное регулирование договоров с участием потребителя излишне, поскольку соответствующие материально-правовые нормы, направленные на защиту потребителя, итак применяются через общий механизм сверхимперативных норм [8, с. 373].

Большинством ученых все же не оспаривается необходимость в установлении ограничений свободы договора с участием потребителя [9, с. 10]. Разница подходов состоит в степени и способах таких ограничений.

Классическим примером второй модели регулирования - недопустимости автономии воли сторон - является ст. 120(2) Закона Швейцарии 1987 г. о международном частном праве (в редакции от 1 июля 2014 г.) [10]. Аналогичные положения содержатся в законодательстве американских штатов Луизиана [11] и Орегон [12]: выбор иностранного права (или права другого штата) должен быть проигнорирован, если потребитель имеет место жительства в одном из этих штатов и сделка была заключена или инициирована там же. В то же время, в отличие от безусловного запрета автономии воли в швейцарском законодательстве, нормы данных штатов все же допускают выбор права в тех случаях, когда потребитель не проживает в Луизиане или Орегоне или если сделка не имеет тесной связи с этими штатами.

Сторонники запрета автономии воли в договорах с участием потребителя указывают на неравное положение сторон: в розничной торговле договоры, как правило, являются договорами присоединения, которые полностью разрабатываются профессиональной стороной, а потребитель не имеет реальной возможности изменять положения договора, включая условие о 


\section{Право и политика $12(192) \cdot 2015$}

применимом праве. Как следствие, профессиональная сторона получает возможность злоупотреблять своим положением и устанавливать, не учитывая интересы слабой стороны - потребителя, в качестве применимого то право, которое наиболее выгодно и наименее обременительно для нее.

Швейцарский коллизионист Ф. Вишер считает, что некоторые договоры, в частности договоры с участием слабой стороны, к которым относятся и договоры с участием потребителя, настолько интегрированы в правовую систему определенной страны, что не могут быть подчинены действию права иного государства [13, с. 27].

Х. Штоль также придерживается мнения о необходимости исключить коллизионный выбор в договорах с участием потребителя. Любая ссылка на применимое право в таком договоре, по мнению исследователя, должна расцениваться как инкорпорация в соглашение положений указанного правопорядка, которые, тем не менее, действуют лишь в тех в пределах, в которых не затрагиваются императивными нормами объективно применимого права (как правило, права страны места жительства потребителя) [14, с. 767].

Сторонники третьей модели регулирования установление исчерпывающего перечня правопорядков, доступных для выбора - опасаются, прежде всего, навязывания слабой стороне права какой-либо страны с неразвитой системой защиты прав потребителя. Предлагается устранять такую угрозу посредством установления возможности выбора применимого права исключительно из строго очерченного перечня правопорядков, имеющих объективную связь с договором [15].

В Регламенте Рим I данная теория реализована в положениях, регулирующих договоры перевозки пассажира и страхования массовых рисков.

Четвертая модель - приоритет защитных императивных норм права по месту жительства потребителя - основана на кумулятивном применении избранного сторонами права и императивных норм права страны места жительства потребителя. Именно данная теория получила воплощение в ст. 6 Регламента Рим І и ст. 1212 ГК РФ.

Возвращаясь к анализу и сравнению ст. 6 Регламента Рим І и ст. 1212 ГК РФ, необходимо отметить некоторое отличие в определении договора с участием потребителя. Так, из текста ст. 6 Регламента Рим I можно видеть, что под договором с участием потребителя в этом документе понимается договор, заключенный физическим лицом (потребителем) с целью, не имеющей отношения к его предпринимательской или профессиональной деятельности, с другим лицом, действующим в ходе осуществления предпринимательской или профессиональной деятельности (профессиональной стороной).

В ГК РФ говорится о договоре, стороной которого является физического лицо, использующее, приобретающее или заказывающее либо имеющее намерение использовать, приобрести или заказать движимые вещи (работы, услуги) для личных, семейных, домашних или иных нужд, не связанных с осуществлением предпринимательской деятельности. Таким образом, в данной статье было использовано определение потребителя, содержащееся в Законе РФ от 07.02.1992 № 2300-1 «О защите прав потребителей», что является разумным решением для целей эффективного правоприменения, поскольку крайне желательно, чтобы коллизионная норма коррелировала с материальными нормами, к которым она отсылает, хотя такой подход и следует порочной российской практике законодательных дублирований [16, с. 14]. Кроме того, достоинство подобного определения заключается также в том, что в него включены лица, лишь намеревающиеся заключить договор, что распространяет действие нормы также на случаи преддоговорных споров. Это весьма полезное положение, поскольку материальными нормами установлены особые требования по предоставлению потребителю информации о товаре, работе или услуге на стадии, предшествующей непосредственному заключению договора [17].

Нельзя не отметить, что в определении договора с участием потребителя, содержащемся в ст. 1212 ГК РФ, отсутствует упоминание о профессиональной стороне, что создает видимость некой диспропорции. Тем не менее, дальнейший текст статьи в своей логической связи не позволяет говорить о наличии здесь какого-либо законодательного пробела.

В чем же может проявляться иностранный элемент в договорах с участием потребителя? Как указывает М. Н. Клевченкова, «в договоре между профессионалом и потребителем трансграничное свойство отношений определяется с учетом следующих обстоятельств: адрес, указанный потребителем, адрес доставки товара либо адрес направления счета расположен в государстве, не совпадающем с постоянным местом нахождения профессионала» [18, с. 57]. Иными словами, иностранный элемент в таких договорах проявляется, прежде всего, в различном домицилии сторон.

Как говорилось выше, автономия воли является генеральной коллизионной привязкой в отношении договоров с участием потребителя. В то же время и Регламент Рим I, и ГК РФ устанавливают, что выбор применимого права не может повлечь за собой ли- 
шение потребителя защиты прав, предоставляемой императивными нормами права страны его места жительства. Для применения данного правила необходимо соблюдение нескольких условий. Прежде всего, деятельность профессиональной стороны должна носить «нацеленный характер»: контрагент потребителя должен либо осуществлять свою деятельность в стране места жительства потребителя, либо любыми способами направлять ее на территорию этой страны или нескольких стран, включая данную страну. Второе обязательное условие: договор должен быть связан с деятельностью профессиональной стороны.

Право страны места жительства потребителя является субсидиарной коллизионной привязкой на тот случай, если стороны договора с участием потребителя не выбрали применимое право самостоятельно и если договор так же был заключен в рамках «нацеленной деятельности» профессиональной стороны.

Ст. 1212 ГК РФ исключает из сферы своего действия ряд договоров.

Во-первых, под исключение подпадают договоры перевозки, поскольку они регулируются специальными коллизионными нормами, отражающими специфику договоров этого типа.

Во-вторых, правила ст. 1212 ГК РФ не распространяются на договоры о выполнении работ или об оказании услуг, если работа должна быть выполнена или услуги должны быть оказаны исключительно в иной стране, чем страна места жительства потребителя (типичный пример - пребывание в гостинице за рубежом). Суть данного исключения состоит в том, что такой договор имеет, очевидно, значительно более тесную связь с правом страны, в которой выполняется работа или оказывается услуга, в связи с чем потребитель не может разумно ожидать применения императивных норм страны его места жительства.

В то же время действие статьи распространяется на договоры об оказании за общую цену услуг по перевозке и размещению (независимо от включения в общую цену стоимости других услуг), в частности на договоры в сфере туристического обслуживания.

Ст. 6 Регламента Рим I содержит более широкий перечень исключений. Помимо случаев, аналогичных названным в ст. 1212 ГК РФ, она также не применяется к договору, имеющему предметом вещное право на недвижимое имущество или аренду недвижимого имущества (при этом договоры таймшера подпадают под регулирование), а также к ряду финансовых инструментов, не являющихся финансовыми услугами.

Современная модель регулирования, получившая отражение в общеевропейском и российском законодательстве и основанная на принципе «нацеленной деятельности», соответствует потребностями современной трансграничной розничной торговли, которая, как правило, осуществляется дистанционными методами посредством интернет-сайтов. Однако для наличия в действиях профессиональной стороны признаков «нацеленной деятельности» недостаточно, чтобы сайт был доступен в стране места нахождения потребителя. Кроме того, как указывается в преамбуле к Регламенту Рим I, используемые интернет-сайтом язык или денежная единица также не имеют значения. В зарубежной литературе рекомендуется профессиональной стороне принимать организационные меры по определению постоянного места жительства потребителей. Например, профессиональная сторона может требовать от потребителя указывать страну места жительства при осуществлении заказа через сайт с последующей блокировкой возможности заказа для потребителей из тех стран, применение императивных норм которого профессиональная сторона желает избежать.

Регулирование, осуществляемое на основании ст. 6 Регламента Рим І и ст. 1212 ГК РФ, порождает ряд практических и теоретических проблем.

Одна из таких проблем метко подмечена Клевченковой М.Н.: «Профессионалы, заключающие договоры с потребителем онлайн, должны нести дополнительные расходы в связи с необходимостью адаптировать свой веб-сайт к юридическим требованиям каждого государства, на чью территорию они направляют свою деятельность» [18, с. 56].

Развивая эту мысль, можно утверждать, что, хотя предприниматели, желающие получать прибыль от осуществления своей деятельности за рубежом, и должны быть готовы нести соответствующие издержки, имеющееся регулирование со значительной долей вероятности вытеснит из международной розничной торговли малый и средний бизнес, который зачастую не имеет возможности получить юридическую консультацию по широкому перечню юрисдикций и учесть ее при осуществлении своей зарубежной деятельности.

Другой, более фундаментальный, вопрос состоит в том, может ли потребитель кумулятивно использовать защитные императивные нормы как избранного в договоре права, так и страны места жительства потребителя, если эти правопорядки предоставляют разные по своему характеру способы защиты прав. Очевидно, что в случае, если один правопорядок предоставляет потребителю 7 дней на немотивированный отказ от договора, а другой - 14 дней, потребитель вправе ссылаться на те нормы, которые в большей степени отвечают его интересам. Однако каким должно быть 


\section{Право и политика $12(192) \cdot 2015$}

правоприменение, если «один правопорядок предоставляет потребителю право на односторонний отказ от заключенного договора, в то время как в другом правопорядке установлены повышенные санкции (например, законная неустойка) за отказ профессиональной стороны от внесудебного удовлетворения правомерных требований потребителя» [15]?

Мнения ученых в данном вопросе расходятся. Так, ряд исследователей высказывается в пользу допустимости такой кумуляции [19, с. 99], указывая на то, что законодательные положения не содержат соответствующего запрета, а значит, потребитель вправе выбирать те нормы, которые являются более выгодными для него, даже если они содержатся в разных правопорядках. Такой подход получил название «теории изюма» (нем. - Rosinentheorie, англ. - cherrypicking) по аналогии с тем, как можно выбирать лучшие изюминки из пирога.

Однако доминирует в доктрине мнение, что кумулятивное применение императивных норм различных правопорядков недопустимо [20, с. 1641]. В противном случае потребитель получал бы необоснованные преимущества.

Однако буква ст. 1212 ГК РФ не позволяет прийти к подобному выводу. Если право страны места жительства потребителя не является правом, применимым к конкретному договору, то применение императивных норм такого правопорядка не может автоматически исключать применение императивных норм права, применимого к договору. Однако применение защитных императивных норм нескольких правопорядков значительно нарушает баланс интересов сторон трансграничного договора с участием потребителя. И дело даже не столько в том, что потребитель в таком договоре получает необоснованно получает объем защиты, на который не мог бы рассчитывать в каждом отдельно взятом правопорядке, относящемся к правоотношению, а в том, что кратно повышаются риски профессиональной стороны, которая может быть принуждена к соблюдению защитных норм нескольких правопорядков. Ст. 1212 ГК РФ необходимо дополнить нормой, которая установит, что при применении защитных императивных норм права страны места жительства потребителя, защитные нормы основного права, применимого к данному договору, не применяются.

При этом остается открытым другой вопрос, который вызывает модель регулирования, установленная Регламентом Рим I и ГК РФ: по чьей инициативе происходит выбор между императивными нормами двух правопорядков?

Некоторые ученые считают, что право выбора должно быть предоставлено той стороне, в интересах которой установлены подобные коллизионные нормы [21, с. 93]. Законодательство некоторых стран, например, Закон Японии о применении законов от 21 июня 1898 г. № 10 (в редакции от 21 июня 2006 г.) в ст. 11, даже требует, чтобы потребитель самостоятельно выступал с ходатайством о применении императивных норм страны своего места жительства и устанавливал их содержание [22].

Другие исследователи [23, с. 280] придерживаются мнения, что определять наиболее выгодные для потребителя нормы должен суд ех officio, поскольку не во всех странах требуется профессиональное представительство потребителей в суде. Очевидно, что не каждый потребитель имеет возможность самостоятельно, без квалифицированной юридической помощи, изучить и сравнить несколько правопорядков, чтобы выбрать наиболее выгодные для себя нормы.

Однако, думается, что возложение на суд такой обязанности привело бы к необходимости суду в каждом трансграничном споре с участием потребителя осуществлять достаточной глубокий анализ иностранного права с целью нахождения в нем защитных норм, выгодных для потребителя. Процесс установления и толкования норм иностранного права крайне громоздок и длителен, едва ли стоит осуществлять его без соответствующего ходатайства потребителя. При этом, конечно, нельзя возложить обязанность установления содержания защитных норм иностранного права на потребителя, этим должен заниматься суд ех officio.

Также в доктрине поднимается вопрос, о том, какие именно императивные нормы получают приоритет перед положениями права, применимого в соответствии с договором: любые императивные нормы или только специальные - регулирующие договоры с участием потребителя. В некоторых правопорядках эта проблема решена: например, Закон Грузии № 1362$11 \mathrm{c} « \mathrm{O}$ международном частном праве» оперирует термином «императивные нормы социальной защиты» [24, с. 63]. Согласно данной концепции выбор права считается недействительным, если он игнорирует императивные нормы, принятые для защиты потребителей, рабочих и служащих от дискриминации.

В поддержку применения любых императивных норм, вне зависимости от того, ориентированы ли они специально на регулирование договоров с участием потребителя, высказывается, в частности, А. В. Асосков, указывая на то, что законодатели отдельных стран могут не вводить специальных материально-правовых норм, ориентируясь в вопроcax защиты прав потребителя на применение общих императивных предписаний [15]. 
Кроме того, применение любых императивных норм права страны места жительства потребителя как общих, так и специальных - устраняет проблему расщепления применимого права, когда отдельные вопросы регулируются императивными нормами разных правопорядков, что излишне усложняет правоприменительный процесс.

Вместе с тем столь расширительное толкование влечет за собой риск применения императивных норм, не имеющих прямого отношения к существу договора с участием потребителя. Так, положения о форме договора также могут быть расценены, как отвечающие интересам потребителя, в то время как форма договора сама по себе не является способом защиты прав потребителя. Подобный подход порождает непредсказуемость правоприменения и нарушает баланс интересов сторон. По этой причине думается, что ограничение круга применимых императивных норм способом, аналогичным содержащемуся в грузинском законодательстве, внесло бы элемент стабильности в коллизионное регулирование рассматриваемых отношений в России.

Коллизионный механизм, созданный посредством ограничения автономии воли возможностью применения более выгодных для потребителя защитных норм права страны места его жительства, действует в отношении лишь так называемых пассивных потребителей - тех, которые заключают договоры с иностранной профессиональной стороной в связи с тем, что последняя направляет свою деятельность на территории стран их места жительства, стимулируя к заключению договоров.

Регламент Рим І устанавливает, что если отсутствуют признаки нацеленной деятельности профессиональной стороны, то право, применимое к договору с участием потребителя, определяется по общим правилам. Таким образом, активные, или мобильные, потребители - те, которые самостоятельно находят профессиональную сторону за пределами страны своего места проживания и заключают с ней договор - приравниваются к профессионалам, и их права не получают коллизионной защиты, предусмотренной для пассивных потребителей. Справедливость такого регулирования регулярно подвергает сомнениям.

Российский законодатель учел самые прогрессивные разработки зарубежной доктрины и включил в ст. 1212 ГК РФ новое положение, аналог которого отсутствует в ст. 6 Регламента Рим І. Смысл этого положения состоит в том, что выбор применимого права в договорах с участием активных потребителей не может повлечь за собой лишение потребителя защиты его прав, предоставляемых императивными нормами той страны, право которой применялось бы к этому договору при отсутствии соглашения сторон о выборе права.

Цель подобного механизма заключается в том, чтобы нивелировать возможные злоупотребления профессиональной стороны, которая, обладая экономической властью, может установить в договоре с участием потребителя в качестве применимого право какой-либо третьей страны с неразвитой системой защиты прав потребителя.

Таким образом, активный потребитель может рассчитывать на защиту его прав, если не со стороны императивных норм страны его места жительства, то, как минимум, со стороны императивных норм страны места нахождения профессиональной стороны (как правило, при отсутствии избранного сторонами права к коммерческим договорам применяется право места нахождения стороны, осуществляющей исполнение, имеющее решающее значение для содержания договора).

Отмечается, что императивные нормы, предоставляющие определенные гарантии потребителю, соответствуют не только частноправовым интересам слабой стороны, но и публично-правовому интересу, который состоит в «обеспечении минимального уровня жизни, правовой защищенности, роста потребительского спроса, укрепления экономической системы государства» в общем и «в правовой защите экономически более слабой стороны» в частности [7, с. 156].

В то же время необходимо выдерживать баланс интересов. Именно по этой причине, наряду со стремлением к предсказуемости и определенности правового регулирования, действующая в России и ЕС модель коллизионного регулирования не предоставляет потребителю возможность выбора применимого права любого из государств, с которым отношение имеет объективную связь.

Российское законодательство восприняло европейскую - наиболее распространенную на сегодняшний день - модель коллизионной защиты прав потребителя, основанную на теории «нацеленной деятельности». Более того, в некоторых вопросах ГК РФ даже превзошел Регламент Рим I в части заботы об интересах потребителя. Однако, как следует из проведенного анализа норм и доктрины, данная модель не лишена определенных недостатков. Решение поставленных проблем осложняется необходимостью соблюсти баланс интересов потребителя и профессиональной стороны. Предлагается дополнить российское законодательство рядом норм, в частности прямо запретить кумулятивное применение защитных императивных норм нескольких правопорядков, ограничить круг применимых императивных норм сферой защиты прав потребителей. 


\section{Библиография:}

1. Гражданский кодекс Российской Федерации (часть третья) от 26.11.2001 № 146-ФЗ // СЗ РФ. 03.12.2001. № 49. Ст. 4552.

2. Convention $80 / 934 / \mathrm{ECC}$ on the law applicable to contractual obligations opened for signature in Rome on 19 June 1980 // OJ L 266 of 9.10 .1980$.

3. Regulation (EC) No 593/2008 of the European Parliament and of the Council of 17 June 2008 on the law applicable to contractual obligations (Rome I) // OJ L 177, 4.7.2008. P. 6-16.

4. Федеральный закон от 30.09.2013 № 260-Ф3 «О внесении изменений в часть третью Гражданского кодекса Российской Федерации» // С3 РФ. 07.10.2013. № 40 (часть III). Ст. 5030.

5. Rühl G. Consumer protection in choice of law // Cornell International Law Journal. - Vol. 44. - 2011. - P. 587 - 592.

6. Hill J. Cross-Border Consumer Contracts. - Oxford, 2008. - 466 p.

7. Асосков А. В. Основы коллизионного права. - М.: Инфотропик Медиа, 2012. - 352 с.

8. Hartley T. Mandatory Rules in International Contracts: the Common Law Approach // Recueil des Cours / Collected Courses of the Hague Academy of International Law. - Vol. 266. - 1997. - P. 337 - 431.

9. Новоселова А. А., Ломакина Е. В. Пределы свободы договора в международных коммерческих отношениях // Международное публичное и частное право. - 2014. - № 1. - С. 9 - 13.

10. Bundesgesetz über das Internationale Privatrecht (IPRG) vom 18. Dezember 1987 (Stand am 1. Juli 2014 ) // AS 19881776.

11. LA. REV. STAT. ANN. § 51:1418 (C) (2014).

12. OR. REV. STAT. $\S 15.320$ (2013).

13. Vischer F. The Principle of the Typical Performance in International Contracts and the Draft Convention // Harmonization of Private International Law by the E.E.C. / Ed. K.Lipstein. - London, 1978. - P. 25 - 30.

14. Stoll H. Internationalprivatrechtliche Probleme bei Verwendung Allgemeiner: ein Diskussionsbeitrag // Festschrift Beitzke zum 70. Geburtstag / Hrsg. O. Sandrock. - Berlin, 1979. - P. 759 - 785.

15. Асосков А. В. Коллизионное регулирование договорных обязательств. - М.: Инфотропик Медиа, $2012 .-640$ с.

16. Гетьман-Павлова И. В., Ерпылева Н. Ю. Российское законодательство по международному частному праву: проблемы совершенствования // Международное публичное и частное право. - 2009. - № 1. - С. 8 - 14.

17. Комментарий к Гражданскому кодексу Российской Федерации, части третьей (постатейный) (под ред. Т. Е. Абовой, М. М. Богуславского, А. Г. Светланова). - М.: Юрайт-Издат, 2004. - 486 с.

18. Клевченкова М. Н. Кодификация договорного права в Европейском союзе // Законодательство и экономика. -2012. - № 7. - C. $53-58$.

19. Philip A. Mandatory Rules, Public Law (Political Rules) and Choice of Law in the E.E.C. Convention on the Law Applicable to Contractual Obligations // Contract Conflicts. The E.E.C. Convention on the Law Applicable to Contractual Obligations: a Comparative Study / Ed. P. North. - Amsterdam, 1982. - P. 78 - 103.

20. Dicey, Morris and Collins on the Conflict of Laws. - London: Sweet \& Maxwell, 2008. - 1950 p.

21. Nishitani Y. Party Autonomy and its Restrictions by Mandatory Rules in Japanese Private International Law: Contractual Conflicts Rules // Japanese and European Private International Law in Comparative Perspective / Ed. J. Basedow, H. Baum, Y. Nishitani. - Mohr Siebeck, 2008. - P. 77 - 103.

22. Act on the General Rules of Application of Laws. Act No. 78 of June 21, 2006 // Asian-Pacific Law and Policy Journal. Vol. 8. - 2006. - P. $138-160$.

23. Basedow J. Consumer Contracts and Insurance Contracts in a Future Rome-I Regulation // Enforcement of International Contracts in the European Union. Convergence and Divergence between Brussels I and Rome I / Eds. J. Meeusen, M. Pertegas, G. Straetmans. - Intersentia nv, 2004. - P. $269-295$.

24. Гетьман-Павлова И. В., Ерпылева Н. Ю. Кодификация международного частного права в Республике Грузия // Международное право и международные организации. - 2012. - № 2. - С. 44 - 75.

25. Некрасов А. И. Основы правового регулирования политикиЕвропейского Союза в области финансовых услуг // Международное право и международные организации / International Law and International Organizations. - $2013 .-2$. - C. 210 - 209. DOI: 10.7256/2226-6305.2013.2.6341.

26. Баталова М. Р. Защитные оговорки в международном частном праве Турецкой Республики // Международное право и международные организации / International Law and International Organizations. - 2014. - 4. - C. 537 - 544 . DOI: 10.7256/2226-6305.2014.4.13480.

\section{References (transliterated):}

1. Rühl G. Consumer protection in choice of law // Cornell International Law Journal. - Vol. 44. - 2011. - P. 587 - 592.

2. Hill J. Cross-Border Consumer Contracts. - Oxford, 2008. - 466 p.

3. Asoskov A. V. Osnovy kollizionnogo prava. - M.: Infotropik Media, 2012. - $352 \mathrm{c}$.

4. Hartley T. Mandatory Rules in International Contracts: the Common Law Approach // Recueil des Cours / Collected Courses of the Hague Academy of International Law. - Vol. 266. - 1997. - P. 337 - 431.

5. Novoselova A. A., Lomakina E. V. Predely svobody dogovora v mezhdunarodnykh kommercheskikh otnosheniyakh // Mezhdunarodnoe publichnoe i chastnoe pravo. - 2014. - № 1. - S. 9 - 13.

6. Vischer F. The Principle of the Typical Performance in International Contracts and the Draft Convention // Harmonization of Private International Law by the E.E.C. / Ed. K.Lipstein. - London, 1978. - P. 25 - 30. 
DOI: $10.7256 / 1811-9018.2015 .12 .17307$

При цитировании этой статьи сноска на dоі обязательна

Интеграционное право и наднациональные организации

7. Stoll H. Internationalprivatrechtliche Probleme bei Verwendung Allgemeiner: ein Diskussionsbeitrag // Festschrift Beitzke zum 70. Geburtstag / Hrsg. O. Sandrock. - Berlin, 1979. - P. $759-785$.

8. Asoskov A. V. Kollizionnoe regulirovanie dogovornykh obyazatel'stv. - M.: Infotropik Media, 2012. - $640 \mathrm{~s}$.

9. Get'man-Pavlova I. V., Erpyleva N. Yu. Rossiiskoe zakonodatel'stvo po mezhdunarodnomu chastnomu pravu: problemy sovershenstvovaniya // Mezhdunarodnoe publichnoe i chastnoe pravo. - 2009. - № 1. - S. 8 - 14 .

10. Klevchenkova M. N. Kodifikatsiya dogovornogo prava v Evropeiskom soyuze // Zakonodatel'stvo i ekonomika. - 2012. - № 7. - S. $53-58$

11. Philip A. Mandatory Rules, Public Law (Political Rules) and Choice of Law in the E.E.C. Convention on the Law Applicable to Contractual Obligations // Contract Conflicts. The E.E.C. Convention on the Law Applicable to Contractual Obligations: a Comparative Study / Ed. P. North. - Amsterdam, 1982. - P. 78 - 103.

12. Dicey, Morris and Collins on the Conflict of Laws. - London: Sweet \& Maxwell, 2008. - 1950 p.

13. Nishitani Y. Party Autonomy and its Restrictions by Mandatory Rules in Japanese Private International Law: Contractual Conflicts Rules // Japanese and European Private International Law in Comparative Perspective / Ed. J. Basedow, H. Baum, Y. Nishitani. - Mohr Siebeck, 2008. - P. 77 - 103.

14. Act on the General Rules of Application of Laws. Act No. 78 of June 21, 2006 // Asian-Pacific Law and Policy Journal. - Vol. 8. $-2006 .-$ P. $138-160$.

15. Basedow J. Consumer Contracts and Insurance Contracts in a Future Rome-I Regulation // Enforcement of International Contracts in the European Union. Convergence and Divergence between Brussels I and Rome I / Eds. J. Meeusen, M. Pertegas, G. Straetmans. - Intersentia nv, 2004. - P. $269-295$.

16. Get'man-Pavlova I. V., Erpyleva N. Yu. Kodifikatsiya mezhdunarodnogo chastnogo prava v Respublike Gruziya // Mezhdunarodnoe pravo i mezhdunarodnye organizatsii. - 2012. - № 2. - S. 44 - 75.

17. Nekrasov A. I. Osnovy pravovogo regulirovaniya politikiEvropeiskogo Soyuza v oblasti finansovykh uslug // Mezhdunarodnoe pravo i mezhdunarodnye organizatsii / International Law and International Organizations. - 2013. - 2. - C. 210 - 209. DOI: 10.7256/2226-6305.2013.2.6341.

18. Batalova M. R. Zashchitnye ogovorki v mezhdunarodnom chastnom prave Turetskoi Respubliki // Mezhdunarodnoe pravo i mezhdunarodnye organizatsii / International Law and International Organizations. - 2014. - 4. - C. 537 - 544 . DOI: $10.7256 / 2226-6305.2014 .4 .13480$ 